\title{
An unusual case of haemoperitonium and bladder invasion due to placenta percreta in the third trimester mimicking threatened uterine rupture
}

\author{
Shama Khan*, Kavita N. Singh, Vineeta Ghanghoriya
}

Department of Obstetrics and Gynaecology, NSCB Medical College, Jabalpur, Madhya Pradesh, India

Received: 05 December 2015

Revised: 07 January 2016

Accepted: 23 January 2016

\section{*Correspondence:}

Dr. Shama Khan,

E-mail: shamakhan3186@gmail.com

Copyright: () the author(s), publisher and licensee Medip Academy. This is an open-access article distributed under the terms of the Creative Commons Attribution Non-Commercial License, which permits unrestricted non-commercial use, distribution, and reproduction in any medium, provided the original work is properly cited.

\begin{abstract}
Placenta praevia percreta is a rare but potentially lethal complication of pregnancy. It has an increasing clinical significance due to its association with previous caesarian section and uterine curettage. Herein we report a patient with placenta percreta, presenting in the emergency as 33 weeks of gestation with acute pain in abdomen and haemorrhagic shock, mimicking silent spontaneous uterine rupture, managed by emergency caesarian section followed by cesarian hysterectomy and bladder repair.
\end{abstract}

Keywords: Percreta, Hemoperitonium, Bladder invasion

\section{INTRODUCTION}

Placenta percreta is a rare but one of the most serious complication of pregnancy. It is characterized by abnormal adherence of the placenta to the uterine wall owing to an absent or faulty decidua basalis. Three forms of placental attachment are distinguished- Placenta accreta, placenta increta, placenta percreta. In placenta accreta the chorionic villi grow into the basal desidua, in placenta increta the chorionic villi penetrate into the musculature and in placenta percreta the villi pass through the myometrium and infiltrate not only the serosa but also the surrounding organs, such as the urinary bladder and the bowel, leading to serious complications. All three types are collectively known as placenta accreta.

The estimated incidence of placenta accrete / increta / percreta was 1.7 per 10,000 maternities overall. However, the incidence is considerably higher in women with both a previous cesarean delivery and placenta previa, occurring in around 1 in every 20 such women. ${ }^{1}$

\section{CASE REPORT}

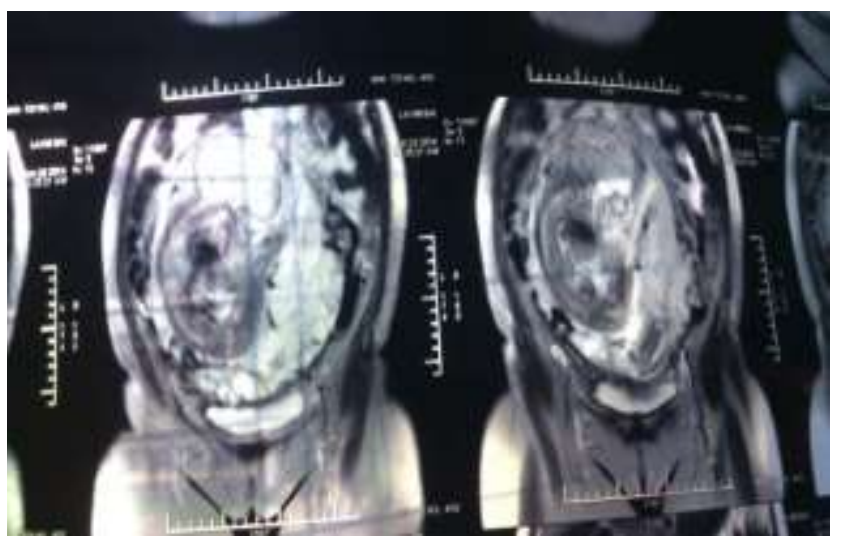

Figure 1: MRI picture showing complete placenta previa with placenta percreta.

A 26-year-old, gravid 2, para 1 with previous one cesarean section, no living issue was referred from 
private hospital and admitted in medical college hospital at 28 weeks of gestation with complain of one episode of minimal vaginal bleeding, which was subsided by conservative management.

Ultrasound scan revealed single viable fetus with central placenta previa. This diagnosis was subsequently confirmed by MRI which shows complete placenta previa with placenta percreta.

Patient was counseled about all possible complications including caesarian hysterectomy. As she lost her first child and was desperate to continue this pregnancy, with informed consent, she was kept hospitalized. Patient was asymptomatic for 3 weeks during the period of hospitalization. At 31 weeks of gestation, patient left the hospital against medical advice due to some personal reasons. After 15 days i.e. at 33 weeks, she was readmitted in emergency hours with thecomplain of severe pain in abdomen but no vaginal bleeding. On examination patient was pale and her pulse rate was 110 bpm, BP 100/70mmHg, FHS 180/min. Due to clinical suspicion of threatened uterine rupture of previous scar, decision for emergency caesarian section was taken. Intraoperatively, on opening the parietal peritoneum, about $500 \mathrm{cc}$ of hemoperitonium was present. Placental vessels were seen on anterior surface, right lateral wall of uterus and were attached to the omentum also. We suspect threatened uterine rupture but previous scar was found intact. Incision was given on relatively vessel free lower uterine segment and a preterm live female baby of $2 \mathrm{~kg}$ was delivered with Apgar score of 3 at 1 minute. Baby was shifted to NICU. Placenta was found to be adherent to the myometrium and vessels were penetrating the full thickness of uterine wall. Placental invasion was also seen upto the urinary bladder. Decision to do cesarean hysterectomy was taken.

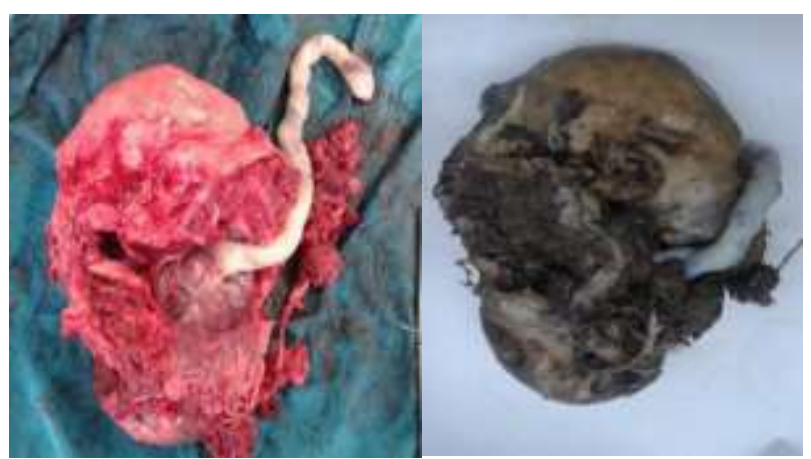

Figure 2: Post hysterectomy specimen showing uterus with placenta in situ.

Adhered part on bladder was excised and repaired in 2 layers. Intraperitoneal drain was inserted. She had significant intrapartum hemorrhage, for which she required 2 units of blood and 4 units fresh frozen plasma. Post operatively, one more unit of blood was transfused. Foley catheter was put for 14 days and then removed after which patient passed urine without difficulty.
Baby died on postnatal day 2 due to early onset sepsis with respiratory distress and intraventricular hemorrhage. Patient was discharged well on post operative day 15. Gross specimen was preserved in museum for study purpose.

\section{DISCUSSION}

Placenta percreta is the most serious abnormal adherence to the uterine wall in which, the decidua basalis is partially or completely absent, and the chorionic villi invade the entire myometrium upto the serosa, with possible involvement of adjacent organs.

Risk of abnormal placentation is increasing with increasing number of repeat caesarian sections which includes low lying placenta praevia as well as placenta percreta. The incidence of bladder invasion is reported in very few cases in literature). In our case bladder invasion was seen without hematuria.

The mechanism for this abnormal placentation in previous caesarian section cases is thought to be a thin, poorly formed decidua in the scarred area of the lower uterine segment,that cannot resist deep invasion by trophoblast. Other factors may include prior curettages, endometritis, maternal age greater than 35 years, increasing parity, sub- mucous fibroid. In our case there wa history of previous caesarean delivery.

Placenta percreta may present in the antenatal period with intraperitoneal or intravesical bleeding.

Intraperitoneal bleeding mimics placental abruption or uterine rupture.

The development of new imaging techniques, such as magnetic resonance imaging (MRI) and transvaginal color Doppler sonography, has allowed antenatal diagnosis of this condition and elective preoperative planning of the obstetric and anesthetic management of these patients.

Currently MRI appears to be the gold standard for the diagnosis of placenta accreta.

Ultrasonography alone is not sufficient to diagnose placental adherence defects, it only assist in the diagnostic process. ${ }^{2}$ In our case, USG revealed placenta previa but missed percreta.

Antepartum planning includes, patient counseling for the suspected diagnosis, potential complications and management options. A preoperative anesthesia consultation, preferred strategy for timing of delivery at 34 weeks of gestation, availability of adequate blood and clotting factors at the time of delivery, and availability of an intensive care unit for postoperative care, as needed. ${ }^{3}$ 
Caesarean hysterectomy with placenta left in-situ, is recommended in the case of life- threatening hemorrhage, which was mandatory in our case. Conservative management may be an option in order to prevent peripartum hysterectomy and to preserve fertility, as long as bleeding remains minimal. Bladder management ranges from simple closure of the bladder hole to ureteric diversion with reimplantation of the ureters, or partial cystectomy. ${ }^{4}$

\section{CONCLUSION}

Placenta percreta is a rare disease with a difficult initial diagnosis. It is an obstetric emergency often associated with massive hemorrhage leading to emergency hysterectomy. Clinical suspicion of placenta percreta is necessary in all patients with low lying placenta and/or history of any scar or surgery on uterus. Ultrasonography should be carried out carefully in such patients. MRI should be used for at risk patients to identify placental location accurately, regardless of the ultrasonography findings.

Early recognition and a multidisciplinary approach for management of placenta percreta in a tertiary care hospital are necessary in reducing the morbidity and mortality associated with this condition.
Funding: No funding sources Conflict of interest: None declared

Ethical approval: Not required

\section{REFERENCES}

1. Fitzpatrick KE, Sellers S, Spark P, Kurinczuk JJ, Brocklehurst P, Knight M. Placenta Accreta/Increta/Percreta in the UK:A national casecontrol study. PLoS ONE. 2012;7:12-e52893.

2. Peker N, Turan V, Ergenoglu M, Yeniel O, Sever A, Kazandi M, Zekioglu O. Assessment of total placenta previa by magnetic resonance imaging and ultrasonography to detect placenta accreta and its variants. Ginekologia Polska. 2013;84:186-92.

3. Robinson BK, Grobman WA. Effectiveness of timing strategies for delivery of individuals with placenta previa and accreta. Obstet Gynecol. 2010;116(4):835-42.

4. Washecka R, Behling A. Urologic complications of placenta percreta invading the urinary bladder: a case report and review of the literature. Hawaii Med J. 2002;61(4):66-9.

Cite this article as: Khan $\mathrm{S}$, Singh $\mathrm{KN}$, Ghanghoriya $\mathrm{V}$. An unusual case of haemoperitonium and bladder invasion due to placenta percreta in the third trimester mimicking threatened uterine rupture. Int $\mathbf{J}$ Reprod Contracept Obstet Gynecol 2016;5:556-8. 